Supplement of Ocean Sci., 15, 199-214, 2019 https://doi.org/10.5194/os-15-199-2019-supplement (c) Author(s) 2019. This work is distributed under the Creative Commons Attribution 4.0 License.

(c) (1)

Supplement of

\title{
The Copernicus Surface Velocity Platform drifter with Barometer and Reference Sensor for Temperature (SVP-BRST): genesis, design, and initial results
}

Paul Poli et al.

Correspondence to: Paul Poli (paul.poli@shom.fr)

The copyright of individual parts of the supplement might differ from the CC BY 4.0 License. 


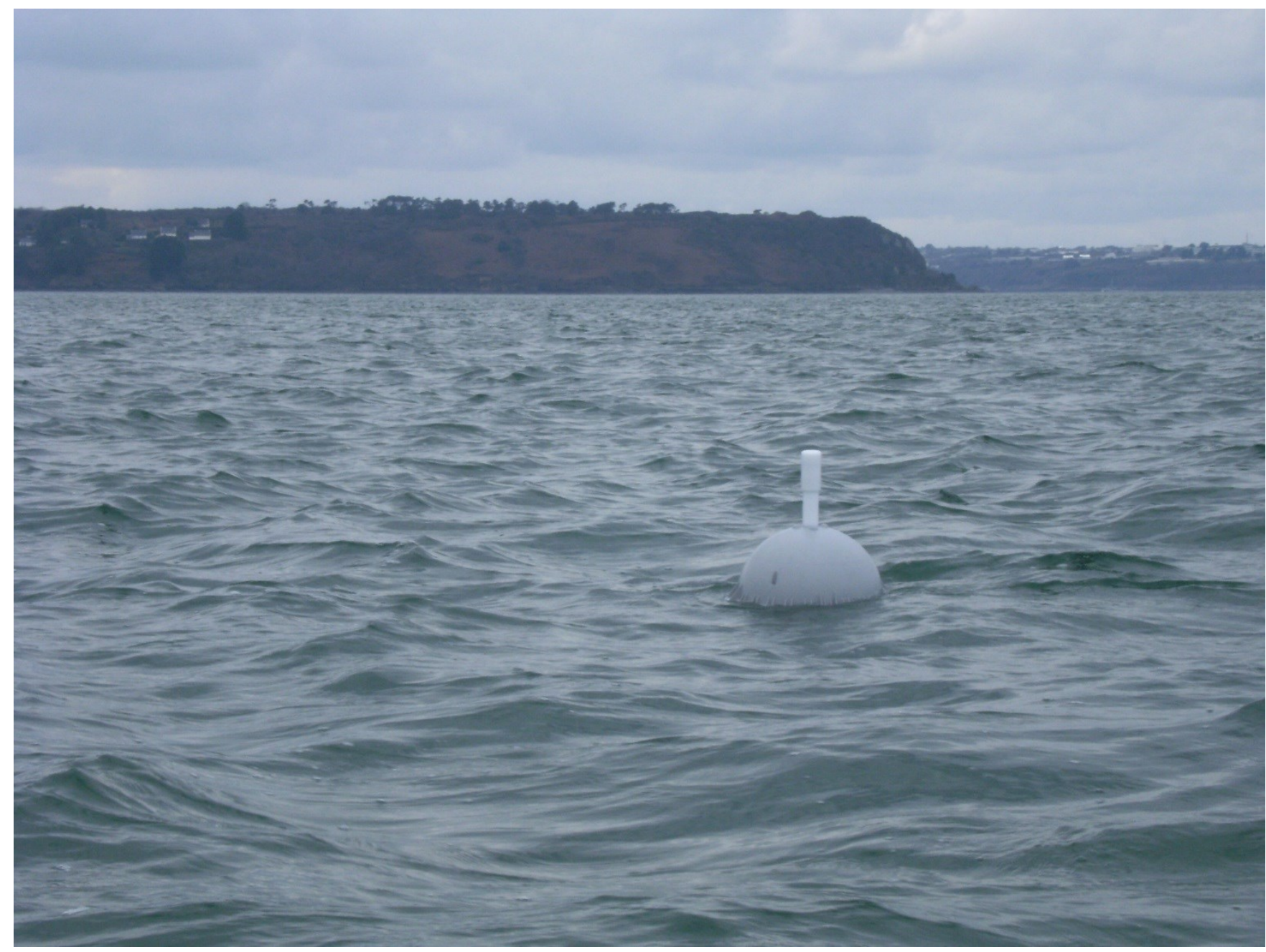

Photo of a SVP-BRST unit deployed for testing in the roadstead of Brest (France). 